Original Paper

\title{
パルスジェット用ろ布における圧力損失特性の 経時変化に及ぼすろ布表面状態の影響
}

\section{Effect of Surface Condition of Fabric Filter on Pressure Drop Evolution in Repeated Pulse-jet Cleaning}

\author{
姚 宇平, ${ }^{\mathrm{a} *}$ 和田 匡司, ${ }^{\mathrm{b}}$ 毛 寧, ${ }^{\mathrm{c}}$ 神谷 秀博, ${ }^{\mathrm{a}}$ 金岡 千嘉男 ${ }^{\mathrm{b}}$ \\ Yuping Yao, Masashi Wada, Ning Mao, Hidehiro Kamiya, Chikao Kanaoka
}

\begin{abstract}
Received 11 April 2007 ; Accepted 5 November 2007
A standard testing method was applied to measure the evolutions of pressure drop during the dust collection by five fabric filters with different surface treatments on a base filtration material. The measurement was repeated until the number of pulse- jet cleaning reaches to 100 . In general, the filtration cycle of a pulse jet cleaning filter consists of three stages, i.e., inner filtration, uniform dust layer formation and surface filtration. However, it was found that the inner filtration stage does not appear when the base filter is laminated with a membrane and entangled fiber layer. The present paper analyzed and discussed the effects of filter surface characteristics and base material structure on the pressure drop evolution during a filtration cycle in terms of the duration of three stages.
\end{abstract}

Keywords : Fabric filter, Surface treatment, Pressure drop characteristic, Pulse-jet cleaning

\section{1. 緒言}

バグフィルターは，排ガス中からの粒子除去性能に 優れ，集塵装置として電気集塵装置とともに広く使用 されている。長期間使用されるろ布は，粉塵の捕集と 払い落としが繰り返されるので，払い落とし特性及び 圧力損失特性の時間変化が特に重要であり, 多くの因 子の影響を受ける。

中井ら ${ }^{1)}$ はガラス繊維ろ布の捕集特性, Silva ら ${ }^{21}$ はろ過速度が粉鹿層の形成及び払い落としに及ぼす影 響，金岡ら ${ }^{3)}$ は平板型ろ布の払い落としプロセス，

a 東京農工大学 生物システム応用科学府

（テ184-8588 東京都小金井市中町 2-24-16）TEL 042-388-7068

BASE, Tokyo, University of Agriculture and Technology

(2-24-16, Nakacho, Koganei, Tokyo 184-8588, Japan)

b 石川工業高等専門学校

（テ929-0392 石川県河北郡津幡町字北中条）TEL 076-288-8161

Ishikawa National College of Technology

(Kitacujo, Tsubata, Kahokugun, Ishikawa 929-0392, Japan)

$c$ 金沢大学 自然科学研究科

（テ920-1192 石川県金沢市角間町）TEL 076-234-6823

Graduate School of Natural Science and Technology,

Kanazawa University

(Kakuma, Kanazawa, Ishikawa 920-1192, Japan)

* 現 中国淅江菲達環境工程有限公司

（解311800 中国浙江省諸暨市望雲路88号）
Calle ら ${ }^{4)}$ は粉塵堆積とサイクル時間について報告し ている。さらに，万布の払い落としに対して，残留粉 塵の量や堆積状態 ${ }^{5 \sim 9)}$, 逆洗空気噴出ノズルの穴径及 びその設置位置 ${ }^{612)}$ ，パルス用压縮空気の貯蔵タンク の容量および圧力 ${ }^{8 \sim 16)}$ ，パルス持続時間 ${ }^{12.15)}$ ， 万過速 度 ${ }^{15 \sim 18)}$ が及ぼす影響等に関する報告がある。さらに 著者らは，毛焼き処理の PPS 製ろ布を用いて，集塵・ 払い落とし操作を繰り返して行い，ある払い落とし操 作から次の払い落とし操作までの 1 集塵サイクル中に おける圧力損失の時間変化を詳細に検討し，粒子の 捕集が，ろ布の内部万過，内部万過から表面ろ過への 遷移，表面ろ過の 3 段階に分けられることを報告し た ${ }^{19)}$ 。

ろ布は，払い落とし性能・粒子捕集性能の向上や長 寿命化を目的に表面処理が施されることが多い。表面 処理には，複層加工，毛焼き処理，鏡面処理などがあ るが, 表面状態は処理法により異なるので圧力損失特 性の時間変化や払い落とし特性が異なると予想され る。しかし，压力損失特性を表面状態と結びつけた報 告は見当たらない。

そこで本研究では, 表面処理および基材の異なる 5 種類のろ布を用い，集塵と払い落としの繰り返し実験 
Table 1 Physical properties of filter medium

\begin{tabular}{|c|c|c|c|c|c|c|}
\hline \multicolumn{2}{|r|}{ Medium } & A & $\mathrm{B}$ & $\mathrm{C}$ & $\mathrm{D}$ & $\mathrm{E}$ \\
\hline \multirow{3}{*}{ Base } & Material & \multicolumn{4}{|c|}{ PPS } & PI \\
\hline & Fiber diameter $(\mu \mathrm{m})$ & \multicolumn{4}{|c|}{14} & 14 \\
\hline & Thickness (mm) & - & - & - & 1.6 & 2.0 \\
\hline \multirow{4}{*}{ Surface } & Surface treatment & membrane & entangled fiber layer & singed & calendered & singed \\
\hline & Material & PTFE & PTFE & - & - & - \\
\hline & Fiber diameter $(\mu \mathrm{m})$ & 0.1 & $1-4$ & - & - & - \\
\hline & Thickness (mm) & 10 & 100 & - & - & - \\
\hline \multicolumn{2}{|c|}{ Weight $\left(\mathrm{kg} / \mathrm{m}^{2}\right)$} & 0.50 & 0.70 & 0.53 & 0.51 & 0.50 \\
\hline \multicolumn{2}{|c|}{ Porosity $(-)$} & - & - & 0.78 & 0.76 & 0.85 \\
\hline \multicolumn{2}{|c|}{ Permeability $\left(\left(\mathrm{cm}^{3} / \mathrm{s}\right) / \mathrm{cm}^{2}\right)$} & 7 & 4 & 21 & 18 & 18 \\
\hline
\end{tabular}

を行い， 万布の表面状態が压力損失特性の経時変化等 へ及ぼす影響について検討した。

\section{2. 実験}

\section{1 試験用万布}

圧力損失特性には，表面状態として表面の平滑性や 表面纎維構造等が影響する可能性が考えられる。本研 究では, 表面状態に特徴的な違いがあるろ布として, 基材の上に粒子剥離性 - 粒子捕集性の優れた表層を設 けた複層加工ろ布から 2 種類, 単層であるが表面が平 滑になるよう処理した平滑処理万布から 2 種類のろ布 を選定し，また，比較のため表面処理が同じで基材の 種類が異なるろ布の計 5 種類のろ布を用いた。各万布 の物性を Table 1 に, 万布表面の走查型電子顕微鏡写 真を Fig. 1 に示す。

ろ布 $\mathrm{A}$ は厚み $10 \mu \mathrm{m}$ 程度の PTFE 膜による複層加 工ろ布で, ろ布表面にはPTFE 膜を延伸して得られ た微細繊維が均一に形成され分布しており, 万布表面 は平滑で表面䋐維構造は密である。万布 B は, PTFE 膜を細裂して作った $1 \sim 4 \mu \mathrm{m}$ 程度の分枝繊維を水流 により約 $100 \mu \mathrm{m}$ 程度の厚さで基材に包絡した複層加 工ろ布である。ろ布表面には分枝㵶維の主幹と思われ る大きい絨維も含め, 表面繊維の絨維径に幅広い分布 が見られる。そのため， ろ布表面は平滑で多少の凹凸 は見られるが表面繊維構造は密である。万布Cは平滑 化処理ろ布で，表面のケバを焼く毛焼き処理を施した ろ布である。表面には所々, 融着䋐維が見られ, 万布 全体に比較的均一に分布している。また, 単首ろ布で あるので䄉維径は大きく表面繊維構造は粗である。ろ 布 Dも平滑化処理ろ布で, 加熱ローラーで鏡面処理を 施したものである。表面には融着絨維が多く, 開口面

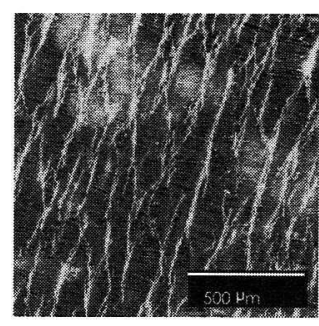

Filter A

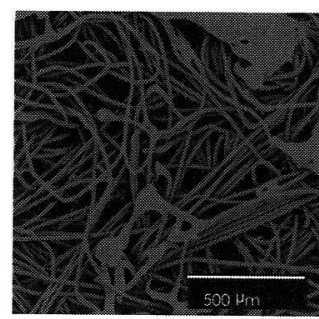

Filter C

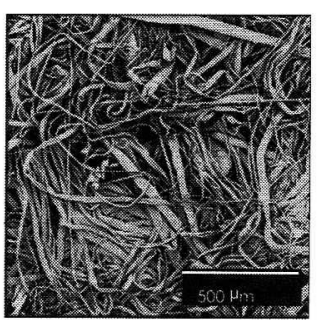

Filter B

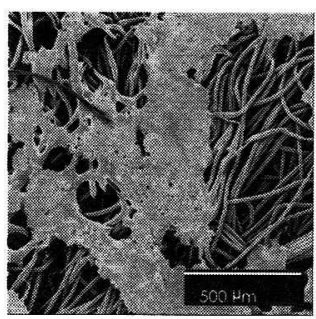

Filter D

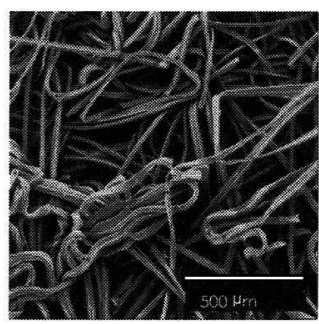

Filter E

Fig. 1 Image of filter surface

積が狭くなっている。また，開口部は不均一に分布し ている。表面䄉維構造は C と同様に粗である。万布 $\mathrm{E}$ は, C と同じ毛焼き処理ろ布だが, 他のろ布と違いPI 基材のろ布である。PPS 製ろ布と平均㵶維径はほぼ 同じであるが，断面形状が円形ではなく非円形であり 


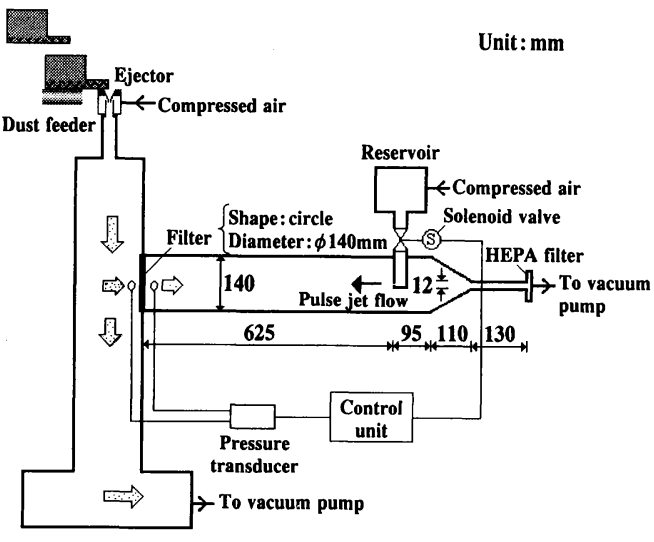

Fig. 2 Schematic of VDI type test equipment

ろ布の空隙率はやや大きい。ろ布表面についてはC と 同様である。

表面にPTFE 䄉維層のあるろ布 B の目付けは高い が，他のろ布の目付けはほぼ同じである。ガス通気度 は, 複層ろ布が小さく単層乃布は大きく, 同じ基材, 目付けでも処理により差がある。

\section{2 実験方法}

実験では，Fig. 2 に示すVDI3926 に準拠した標準 万布評価装置 ${ }^{20)}$ に新品の試験用ろ布を装着し, 試験 用粉体 JIS\#10（フライアッシュ，平均粒子径 $5.2 \mu \mathrm{m}$, 幾何標準偏差 1.2) を $5 \mathrm{~g} / \mathrm{m}^{3}$ の一定濃度で供給し, ろ 過速度 $5 \mathrm{~cm} / \mathrm{s}$ で, 万布の圧力損失が $1 \mathrm{kPa}$ に到達す まで粉鹿を捕集した。その後, 万過気流は止めずにろ 布後方に設置した噴射ノズルより $500 \mathrm{kPa}$ の加圧空気 を $250 \mathrm{~ms}$ 噴射し, 堆積粉塵の逆洗, 払い落としを行 う。以上の集塵と払い落としのサイクルを 100 回繰り 返し行った。実験時間中, 万布の圧力損失は $1 \mathrm{~Hz} て ゙$ 測定した。また，供給粉塵濃度の安定性はろ布上流に 設置した光散乱濃度計で常時監視した。実験の主な条 件を Table 2 に示す。

\section{3. 実験結果及び考察}

ろ布 A， C，Dについて，集塵時の圧力損失 $\Delta P$ の 時間変化を払い落とし回数 $N$ をパラメータとして Figs. 3 5 に示す。

万布 A, C, Dの圧力損失変化は, $N=1$ の場合, 集塵開始直後は緩やかで, ある程度時間が経過した後 に増加する傾向がある。これは, 新しいろ布では粒子 がろ布内部に侵入し，表面にケーキ層を形成するまで に時間がかかるためと考えられる。 $N=10,100$ で比 較すると, 压力損失の時間変化パターンはろ布により
Table 2 Experimental conditions

\begin{tabular}{lc}
\hline Dust type & JIS \# 10 \\
Dust mean diameter $(\mu \mathrm{m})$ & 5.2 \\
Dust standard deviation $(\mu \mathrm{m})$ & 1.2 \\
Filtration velocity $(\mathrm{cm} / \mathrm{s})$ & 5 \\
Dust concentration $\left(\mathrm{g} / \mathrm{m}^{3}\right)$ & 5 \\
Tank pressure $(\mathrm{kPa})$ & 500 \\
Pulse duration $(\mathrm{s})$ & 0.25 \\
Pressure drop before cleaning $(\mathrm{Pa})$ & 1000 \\
\hline
\end{tabular}

異なる。既報19) では，万布の圧力損失の時間的変化率 により集塵の段階を, $\frac{\mathrm{d} \Delta p}{\mathrm{~d} t}$ が時間とともに増加し下 に凸の圧力損失変化をする内部万過, $\frac{\mathrm{d} \Delta p}{\mathrm{~d} t}$ が時間と ともに減少し上に凸の圧力損失変化をする内部ろ過か ら均一な粉塵層が形成される表面ろ過への遷移, $\frac{\mathrm{d} \Delta p}{\mathrm{~d} t}$ が一定となり直線的圧力損失変化をする表面ろ過段階 に分類した。この傾向は，万布 C，Dでは観察された が，ろ布 Aでは払い落とし直後から圧力損失が上に凸 な増加をした後に, 時間に対して直線的に増加してお り，N=10 では内部万過はほとんど起きていないと 考えられる。また， 万布Dでは， $N=10$ の $t=300 \mathrm{~s}$ で見られるように，表面ろ過段階中に階段状に跳ね上 がる現象が時おり観察される。これは，前述のように 表面の融着䋐維により開口部が不均一に分布している ため，気流が一部の開口部に集中する。粉鹿が選択的 に開口部に堆積・閉鎖するため, 圧力損失が急増し, ある圧力損失に達すると, 他の部位に気流が流れるた め, このようなステップ状の圧力損失変化が観察され たと考えられる。複層加工のろ布 Bは万布 $\mathrm{A}$ 之, 毛焼 き処理のろ布 $\mathrm{E}$ は万布 $\mathrm{C}, \mathrm{D}$ と同じ傾向を示し, 表面

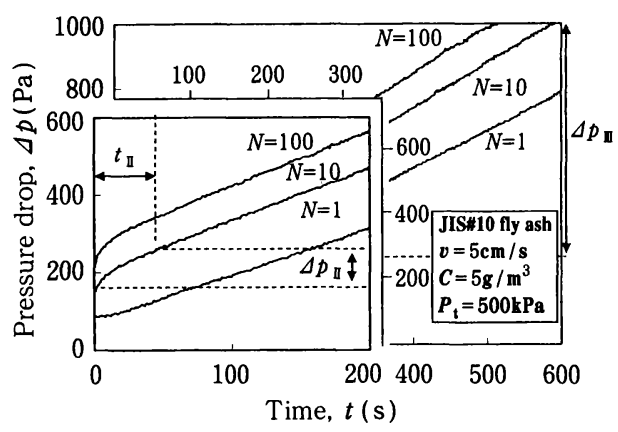

Fig. 3 Change in pressure drop with time (filter A) 


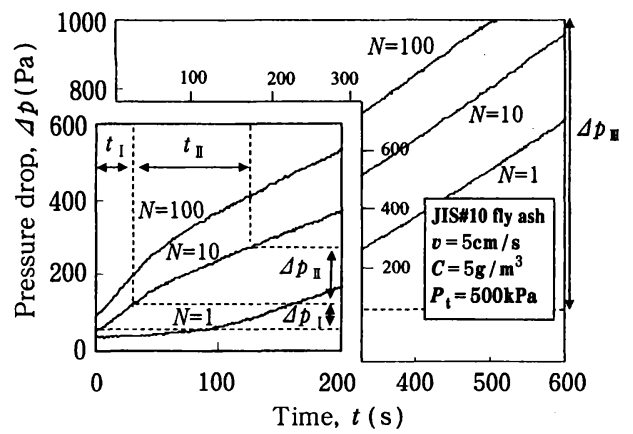

Fig. 4 Changing of pressure drop with time (filter C)

処理状態が同様であれば圧力損失の経時変化傾向が似 ている。次に, 払い落とし回数の増加に伴う集じん・ 払い落とし特性の変化に及ぼすろ布の種類の影響を検 討した。

\section{a ）集塵サイクル時間の払い落とし回数に伴う変化}

集塵サイクル時間 $T$ は払い落とし後压力損失 $\Delta p$ が $1 \mathrm{kPa}$ に達し, 次の払い落としを行うまでに要した 時間で, Fig. 6 に各ろ布の払い落とし回数に伴う変化 を示す。いずれのろ布も初期の段階で $T$ は急激に短 くなるが, その後は, 䅼やかに減少している。 $N=$ 100 では, Eが最も長く，Cと A ほほぼ等しく，B，D の順に短くなっている。フィルタの処理方法との関係 を見ると，毛焼き処理（C, E) が長く，鏡面処理 (D) が短くなる傾向がある。

b ）残留圧力損失の払い落とし回数に伴う変化

残留圧力損失は払い落とし直後の圧力損失で,

Figs. 3 5 では各曲線の $t=0$ での圧力損失に対応す る值である。Fig. 7 に各万布の残留圧力損失増加量 $\Delta P_{\mathrm{r}}$ の払い落とし回数 $N$ に伴う変化の平均的挙動を, Table 3 に実験終了後の残留粉塵質量 $m$ を示す。な お，ここでは測定值から清净ろ布の初期圧力損失 $\Delta P_{0}$ (Figs. 3 5 に示した $N=1, t=0$ での值) を差し引い

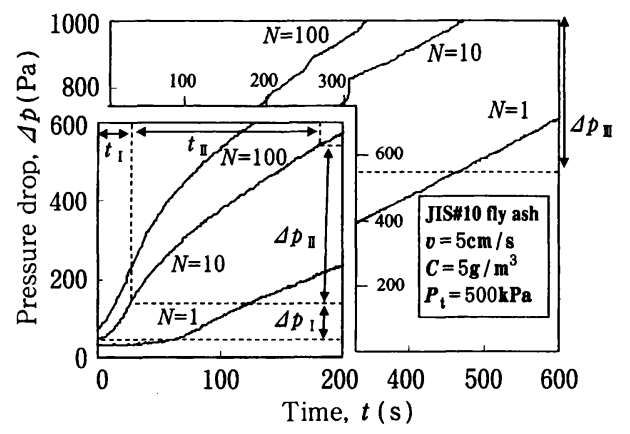

Fig. 5 Change of pressure drop with time (filter D)

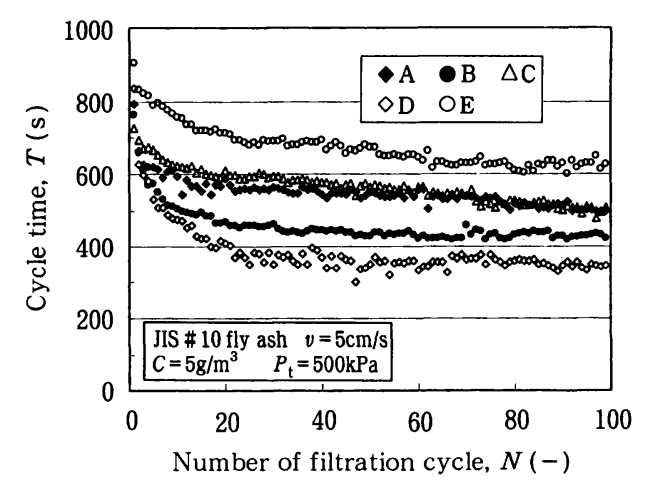

Fig. 6 Relation between cycle time and number of filtration cycle

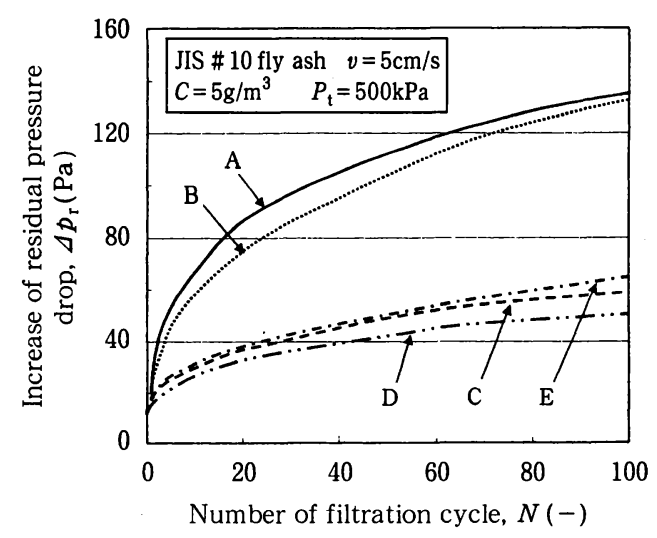

Fig. 7 Relation between increase of residual pressure drop and number of filtration cycle

た值（測定圧力損失一清净ろ布圧力損失）を残留圧力 損失增加量 $\Delta P_{\mathrm{r}}$ とした。

残留圧力損失増加量 $\Delta P_{\mathrm{r}}$ は初期に急激に増加する が，払い落とし回数とともに緩やかになっている。 $N=100$ では, $\Delta P_{\mathrm{r}}$ は D, C, E , B , A の順に大きくな り, 単層乃布 $(\mathrm{C}, \mathrm{D}, \mathrm{E})$ 之複層乃布 ( $\mathrm{A}, \mathrm{B})$ の 2 グ ループに分かれる結果となった。ただし，経験的には 単層乃布は圧力損失の初期值が低いが, 払い落とし回 数に伴う残留圧力損失の増加が大きく安定にも時間が かかるのに対して, 複層加工ろ布ではろ布自身の圧力

Table 3 Mass of residual dust, $m\left(\mathrm{~g} / \mathrm{m}^{2}\right)$

\begin{tabular}{c|c|c|c|c}
\hline Filter A & Filter B & Filter C & Filter D & Filter E \\
\hline 24.0 & 67.0 & 98.0 & 101.0 & 130.0 \\
\hline After 100 cycles \\
JIS \# 10 fly ash \\
$v=5 \mathrm{~cm} / \mathrm{s}$ \\
$C=5 \mathrm{~g} / \mathrm{m}^{3}$ \\
$P_{\mathrm{t}}=500 \mathrm{kPa}$
\end{tabular}




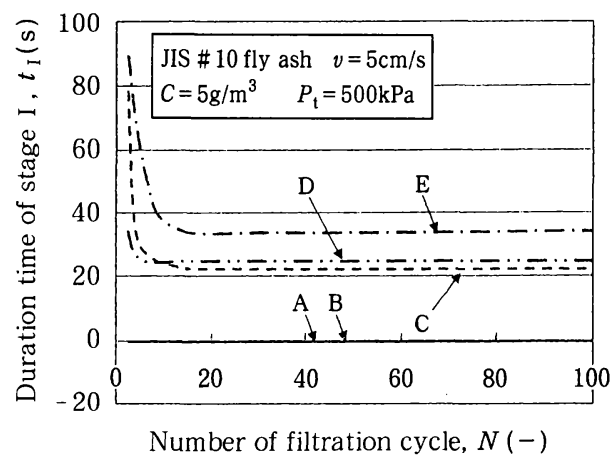

Fig. 8 Relation between duration time of stage I and number of filtration cycle

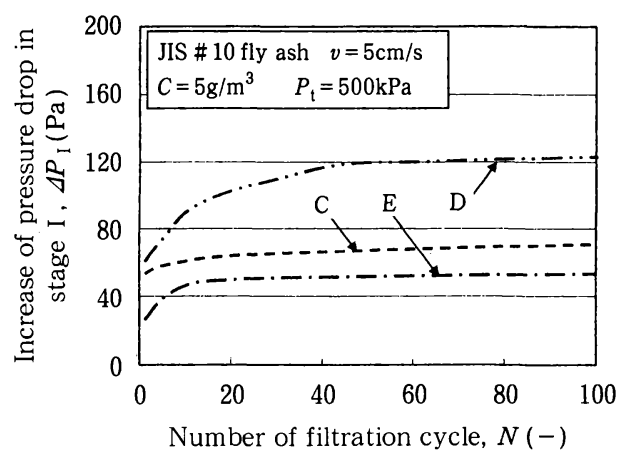

Fig. 9 Relation between increase of pressure drop in stage I and number of filtration cycle

部万過段階での圧力損失増加 $\Delta p_{\mathrm{I}}$ は, $\mathrm{E}, \mathrm{C}, \mathrm{D}$ の順に 大きく, 基材の構造より毛焼き処理 ( $\mathrm{E}, \mathrm{C}$ ), 鏡面処 理（D）と表面処理別の順となっている。万布 D とC は $t_{\mathrm{I}}$ はほぼ等しいが, $\Delta p_{\mathrm{I}}$ は大きく異なる。これ は，前述したように表面の開口部に気流が集中するた

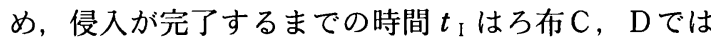
同程度だが，Dでは限られた開口部に粒子が樑く侵入 するため， $\Delta P_{\mathrm{I}}$ が大きくなると考えられる。ろ布 $\mathrm{E}$ は空間率が大きいため, 内部万過時間 $t_{\mathrm{I}}$ が長くなる が， 万布内部に空隙がある段階で表面ろ過に移行する

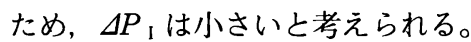

d) 遷移段階中の圧力損失曲線の払い落とし回数に伴 う変化

内部万過から表面ろ過への遷移段階の持続時間 $t_{\text {II }}$ の平均的挙動を Fig. 10 に，この時間内での増加圧力 損失 $\Delta p_{\text {II }}$ の払い落とし回数に伴う変化の平均的挙動 を Fig. 11 に示す。遷移段階の持続時間 $t_{\text {II }}$ は A, B, E, $\mathrm{C}, \mathrm{D}$ の順に長く, $\mathrm{E}$ と C はほぼ同等で, 複層加工 (A, B)，毛焼き処理（C, E)，鏡面処理（D）と表面

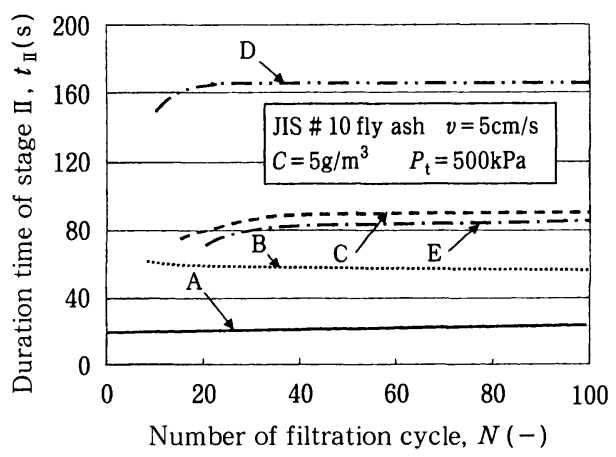

Fig. 10 Relation between duration time of stage II and number of filtration cycle 


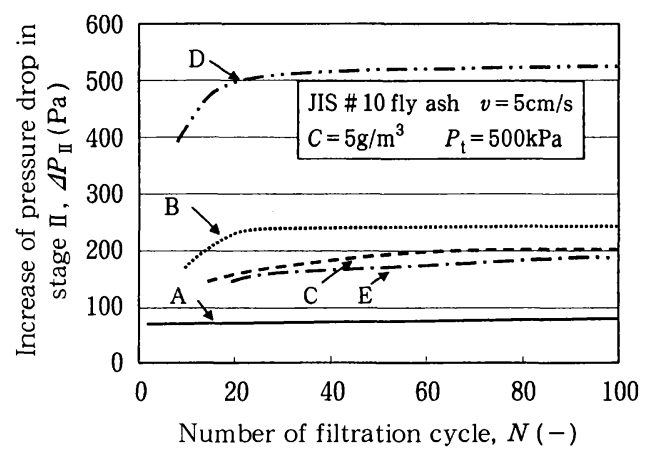

Fig. 11 Relation between increase of pressure drop in stage II and number of filtration cycle

処理別の順となっている。複層万布では，万布Aが初 期から，ろ布 Bも少ない払い落とし回数で一定值を示 しているのに対し，単層乃布 (C, E, D) では一定とな るまでに必要な払い落とし回数が多い。遷移段階の圧 力損失 $\Delta p_{\text {II }}$ は, $\mathrm{A}, \mathrm{E}, \mathrm{C}, \mathrm{B}, \mathrm{D}$ の順で増加し, $\mathrm{E}$ と C はほぼ同等である。つまり, 表面近傍の䄉維径が小さ いろ布ほど $t_{\text {II }}$ が短く, また, 融着瀻維が多いろ布ほ

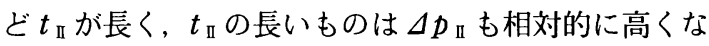
る傾向がある。これは, 試験終了後の各万布表面に粉 塵層が部分的に残留した状態は見られなかったので, 表面近傍㵶維の繊維径や融着緘維の割合に起因する平 坦なケーキ層の形成されやすさの違いと考えられる。 ただし，ろ布 B はろ布 $\mathrm{C}, \mathrm{E}$ より $t_{\mathrm{II}}$ が短いが, $\Delta p_{\mathrm{II}}$ は ろ布 $\mathrm{C}, \mathrm{E}$ より大きくなっている。複層乃布の表面綫 維層の空間率は小さい上に, 粉塵の堆積後のろ布の空 間率がさらに低下したためと考えられる。さらに， ろ 布 $\mathrm{C}, \mathrm{E}$ の結果から， $t_{\mathbb{I}}, \Delta p_{\mathbb{I}}$ ともにろ布基材の違い による影響は小さく, 表面処理状態が $t_{\mathbb{I}}, \Delta p_{\mathbb{1}}$ には 大きく影響していると考えられる。また，万布 $\mathrm{D} の$ $t_{\text {II }}, \Delta p_{\text {II }}$ が特に大きいのは, 前述のように開口面積 が狭く開口部が不均一に分布している表面特性による もので，優先的に大きな開口部から粉塵が詰まってい くため, 均一なケーキ層になるまでの遷移期間が長く なると考えられる。

e ）表面乃過段階中の圧力損失曲線の払い落とし回数 に伴う変化

Table 4 に，表面乃過段階における各ろ布の 6 秒平 均の圧力損失増加率を示す。差はわずかであるが, 複 層加工 (A, B) が低く, 毛焼き処理 $(\mathrm{C}, \mathrm{E})$, 鏡面処理 （D）と表面処理別の順で増加している。本実験では粉 塵流入濃度が一定であったにもかかわらず， 万布間で 圧力損失増加率に差があるのは，万布表面の堆積粉塵
Table 4 Increase rate of pressure drop in stage III

\begin{tabular}{c|c}
\hline Filter & $\Delta p_{\text {III }} / \Delta t(\mathrm{~Pa} / \mathrm{s})$ \\
\hline $\mathrm{A}$ & 1.36 \\
\hline $\mathrm{B}$ & 1.37 \\
\hline $\mathrm{C}$ & 1.47 \\
\hline $\mathrm{D}$ & 1.66 \\
\hline $\mathrm{E}$ & 1.40 \\
\hline
\end{tabular}

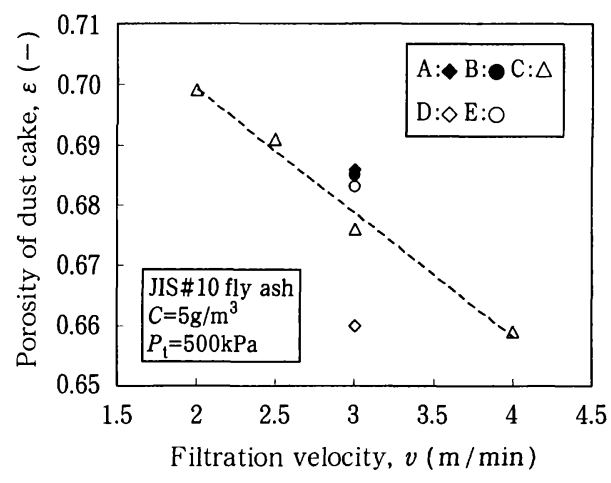

Fig. 12 Porosity of dust cake

の状態が異なっている可能性が考えられる。そこで, 各ろ布上に形成された粉塵堆積層の空隙率を推定し た。粉体層の圧力損失をよく表現しているといわれて いる Kozeny・Carman 式を用いると, 圧力損失増加 率は次式で表される。

$$
\frac{\mathrm{d}(\Delta p)}{\mathrm{d} t}=\frac{180(1-\varepsilon) C \mu v}{d_{\mathrm{p}}^{2} \varepsilon^{3} \rho}
$$

本実験では, 粉塵濃度 $C$, ガスの粘度 $\mu$, 気流速度 $v$, 粉塵の粒子径 $d_{\mathrm{p}}$, 粉塵の粒子密度 $\rho$ は一定なので 圧力損失増加率の差は空隙率 $\varepsilon$ の違いによると考える ことが出来る。そこで, 上式を用い压力損失増加率か ら算出した各ろ布上の粉鹿堆積層の空隙率 $\varepsilon$ を Fig. 12 に示す。同一のろ布上に気流速度, 粉鹿濃度が同 じ条件であれば，ろ布上では同一の空隙率の粉塵堆積 層を形成すると考えられる。実験からはろ布により異 なる空隙率 $\varepsilon$ が得られ，大きい順に $\mathrm{A}, \mathrm{B}, \mathrm{E}, \mathrm{C}, \mathrm{D}$ で 鏡面処理のろ布 $\mathrm{D}$ が特に小さく，万布の表面が粗いほ ど空隙率 $\varepsilon$ が小さい結果となった。さらに，ろ布Cに ついてろ過流速 3.33 $6.67 \mathrm{~cm} / \mathrm{s}$ の範囲で同様の実験 を行い, 圧力損失増加率より求めた粉塵堆積層の空隙 率 $\varepsilon$ をFig. 12 に示した。Eq. (1) が示すとおり，同 一ろ布であれば流速が変わると粉塵堆積層の空隙率が 
変わることが分かる。このことから, 同一の流速条件 でも粉塵堆積層の空隙率が変わるのは, 万布に流れ込 む気流の流速は同じでも粉塵をろ過している部分での 実効的な流速が違っていることが原因と考えられる。 実効的な流速は， 万布の空間率もしくは表面の開口面 積により異なると考えられるが，ろ布 $\mathrm{A} 〜 \mathrm{D}$ は同一基 材であり， 万布の空間率がやや大きい基材のろ布 $\mathrm{E} も$ 他のろ布に比べ粉塵堆積層の空隙率の差がないので, ろ布の空間率ではなくろ布表面の開口面積の影響が大 きいと考えられる。万布 $\mathrm{D}$ は開口部が少なく，実質流 速が速いため，特に空隙率が低くなったと考えられ る。

\section{4. 結 論}

ろ布の表面状態が圧力損失特性に及ぼす影響を検討 するため, 表面処理方法及び基材の異なる 5 種類のろ 布を用いて集塵・払い落としの繰り返し実験を行い, 払い落としの残留圧力損失及び各集塵過程について以 下の結論を得た。

1 ) 単層乃布 (C, D, E) では圧力損失の経時変化から 3 段階の集鹿段階が観察されたが，複層乃布（A，
B）では 1 段階目がほとんど観察されなかった。

2 ）払い落とし直後の残留圧力損失 $\Delta p_{\mathrm{r}}$ は複層乃布 (A, B) が単層乃布 $(\mathrm{C}, \mathrm{D}, \mathrm{E})$ より大きい。 $N=100$ 後の残留粉塵量は複層万布のほうが多いことからろ 布表面近傍の粉塵残留量が $\Delta P_{\mathrm{r}}$ に影響すると考え られた。

$3)$ 内部万過段階が観察された単層乃布 $(\mathrm{C}, \mathrm{D}, \mathrm{E})$ で の内部万過段階の持続時間 $t_{\mathrm{I}}$ はろ布の空隙率の高 いEで長く， C, D は短い。この段階での圧力損失 変化 $\Delta P_{\mathrm{I}}$ は毛焼き処理 $(\mathrm{C}, \mathrm{E})$ 上り, 鏡面処理 $(\mathrm{D})$ のほうが大きい。

4 ）内部万過が終了し，均一なケーキ層が形成される までの遷移段階の持続時間 $t_{\text {II }}$ は複層乃布で短く, 単層乃布で長い。压力損失 $\Delta P_{\mathrm{II}}$ は $t_{\mathrm{II}}$ が長いろ布ほ ど，大きい傾向があるが，分枝䄉維による複層乃布 $\mathrm{B}$ は $t_{\text {II }}$ が短いわりに, $\Delta P_{\text {II }}$ が大きかった。

5 ）表面乃過段階での圧力損失変化 $\Delta P_{\text {III }}$ は，形成さ れるケーキ層の空隙率に依存すると考えられ，開口 部が少ないろ布Dでは実効的なろ過速度が速く，空 隙率が他のろ布より小さいため, $\Delta P_{\text {III が高いと推測 }}$ された。

\section{Nomenclature}

C : dust concentration

$d_{\mathrm{p}}$ : particle diameter

$m$ : residual dust

$N$ : cycle number

$\Delta p \quad$ : pressure drop of filter

$\Delta p_{0}$ : initial pressure drop of filter

$\Delta p_{\mathrm{I}}$ : increase of pressure drop in stage I

$\Delta p_{\text {II }}$ : increase of pressure drop in stage II

$\Delta p_{\mathrm{III}}$ : increase of pressure drop in stage III

$P_{\mathrm{t}} \quad$ : pressure of pulse- jet

$\begin{array}{rll}\left(\mathrm{g} / \mathrm{m}^{3}\right) & R & \text { : parameter of interruption } \\ (\mathrm{m}) & t & \text { : filtration time } \\ \left(\mathrm{g} / \mathrm{m}^{2}\right) & t_{\mathrm{I}} & \text { : duration time of stage I } \\ (-) & t_{\text {II }} & \text { : duration time of stage II } \\ (\mathrm{Pa}) & t_{\text {III }} & \text { : duration time of stage III } \\ (\mathrm{Pa}) & T & \text { : cycle time } \\ (\mathrm{Pa}) & v & \text { : filtration velocity } \\ (\mathrm{Pa}) & \varepsilon & \text { : porosity of dust cake } \\ (\mathrm{Pa}) & \mu & \text { : gas viscosity } \\ (\mathrm{kPa}) & \rho & \text { : particle density }\end{array}$

\section{References}

1) Nakai, A. and K. Iinoya : "Experimental Study on Dust Collection Performance of Glass Bag Filter Cloths", J. Soc. Powder Technol., Japan, 9, 399-402 (1972)

2 ) Silva, C. R. N., V. S. Negrini, M. L. Aguiar and J. R. Coury: "Influence of gas velocity on cake formation and detachment", Powder Technol., 101, 165-172 (1999)

3 ) The Association of Powder Process Industry and Engineering of Japan: "The technology and equipment of dust collection”, p. 67, Nikkan Kogyo Shinbun Ltd. (1997)

4 ) Calle, S., P. Contal, D. Thomas, D. Bemer and D. Leclerc: "Description of the clogging and cleaning cycles of filter medium", Powder Technol., 123, 40-52 (2002)
5 ) Allen, R. W. K., H. G. D. Goyder and K. Morris : "Modeling medium movement during cleaning of pulsejet fabric filters", Chem. Eng. Res. and Design, 77 (3), 223-230 (1999)

6 ) Dennis, R., J. E. Wilder and D. L. Hammon : "Predicting pressure loss for pulse jet filters", J. Air Pollution Control Assoc., 31 (9), 987-992 (1981)

7 ) Humphries, W. and J. J. Madden : "Fabric filtration for coal-fired boilers : dust dislodgement in pulse jet filters", Filtration and Separation, 20 (1), 40-44 (1983)

8 ) Morris, W. J. : "Cleaning mechanisms in pulse jet fabric filters", Filtration and Separation, 21 (1), 50-54 (1984)

9 ) De Ravin, M., W. Humphries and R. Postle : “A model 
for the performance of a pulse jet filter", Filtration and Separation, May/June, 201-207 (1988)

10) Lu, H. C. and C. J. Tsai: "A pilot-scale study of the design and operation parameters of a pulse- jet baghouse", Aerosol Sci. and Technol., 29 (6), 510-524 (1998)

11) Lu, H. C. and C. J. Tsai : "Influence of design and operation parameters on bag-cleaning performance of pulse- jet baghouse", J. Environmental Eng., 125 (6), 583-591 (1999)

12) Lu, H. C. and C. J. Tsai : "Numerical and experimental study of cleaning process of a pulse-jet fabric filtration system", Environmental Sci. and Technol., 30 (11), 3243-3249 (1996)

13) Sievent, J. and F. Loeffer : "Fabric cleaning in pulsejet filter", Chem. Eng. PRocess, 26, 179-183 (1989)

14) Morris, K. : "Expert system control of fabric filters", Filtration and Separation, 28 (4), 275-280 (1991)

15) Simon, X., D. Thomas, D. Bemer, S. Calle, R. Regnier and P. Contal: "Influence of cleaning parameter on pulse- jet filter bag performance", Filtration, 4 (4), 253-260 (2004)

16) Tsai, C. J., M. L. Tsai and H. C. Lu : "Effect of filtration velocity and filtration pressure drop on the bag cleaning performance of pulse-jet baghouse", Separation Sci. and Technol, 35 (2) 211-226 (2000)
17) Klingel, R. and F. Loffer: "Dust collection and cleaning efficiency of a pulse-jet fabric", Filtration and Separation, 20 (3), 205-208 (1983)

18) Leith, D., M. W. First and H. Feldmann: "Performance of a pulse-jet filter at high filtration velocity - II Filter cake redeposition", J. Aerosol Pollution Control Assoc., 27, 636-642 (1977)

19) Kanaoka, C. and Y. Yao: "The time dependency of pressure drop in a flat type pulse jet fabric filter", Kagaku kogaku Ronbunshu, 29, 267-271 (2003)

20) VDI/DIN 3926 : "Testing of Cleanable Filter Media standard test for evaluation of cleanable filter media", VDI/DIN Manual Air Pollution Prevention, Vol. 6. Verein Deutscher Ingenieure.

21) Kanaoka, C., M. Furuuchi and J. Murai : "The dust cleaning mechanism of a pulse jet type bag filter". J. Soc. Powder Technol., Japan, 31, 424-429 (1994)

22) Mao, N., Y. Yao and C. Kanaoka : “Comparison of fil tration performance of cleanable fabric filters measured by VDI and JIS testing rigs", Advanced Powder Technol., 17, 85-97 (2006)

23) The Association of Powder Process Industry and Engineering of Japan: “The technology and equipment of dust collection", p. 33, Nikkan Kogyosinbun Ltd. (1997) 